\title{
ETNOBOTÂNICA E EDUCAÇÃO ESCOLAR INDÍGENA: UMA POSSIBILIDADE ENTRE OS PAITER SURUÍ
}

\section{Ethnobotanics and Indigenous School Education: A Possibility Among the Paiter Suruí}

\author{
Nauama Dias Suruí ${ }^{1}$ \\ Chicoepab Suruí Dias ${ }^{2}$
}

\begin{abstract}
Resumo: Os povos indígenas em seu contexto cultural possuem uma relação muito próxima com a natureza, especialmente com as plantas. A etnobotânica é a ciência que visa registrar, resgatar e valorizar esses conhecimentos. Diante disso, o objetivo da pesquisa foi relatar os conhecimentos etnobotânicos com enfoque nas plantas medicinais do povo indígena Paiter Suruí de Rondônia e incentivar a valorização dos mesmos por meio da educação escolar indígena. Para tanto, fez-se um estudo bibliográfico explorando principalmente trabalhos acadêmicos realizados por pesquisadores do próprio povo. O resultado da pesquisa mostrou que o povo Paiter Suruí possui tradicionalmente um vasto conhecimento etnobotânico, há uma variedade de plantas medicinais para doenças como diarreia, conjuntivite e inflamações. No entanto, o estudo apontou que esses conhecimentos vêm se perdendo ao longo do tempo devido ao contato com as comunidades não indígenas e com um modelo de escola que não se preocupa com o etnoconhecimento. Assim, a pesquisa finaliza propondo aos professores das escolas indígenas que utilizem métodos de ensino que promovam a valorização da cultura e que permitam que os alunos indígenas participem ativamente no processo de ensino.
\end{abstract}

Palavras-chave: Etnoconhecimento. Povos indígenas. Ensino. Plantas medicinais.

\begin{abstract}
Within their cultural context, indigenous peoples have an extremely close relation with nature, especially with plants. Ethnobotany is a discipline that aims to document, maintain, and valorize these types of knowledge. Given this background, the current research aims to document the ethnobotanical knowledge, specifically in relation to plants, of the indigenous group the Paiter Surui of Rondonia, with the aim of valuing the importance of this knowledge through increased indigenous education initiatives. In order to accomplish this, we conducted a bibliographic study of the academic research conducted by those working with the Paiter Suruí. The results of this research show that the Paiter Suruí traditionally have maintained a vast ethnobotanical knowledge, including a variety of traditional medicinal remedies for maladies such as diarrhea, conjunctivitis, and inflammations. However, the study revealed that this knowledge has dissipated over time, mainly due to contact with non-indigenous communities, and with an educational model that ignores ethnocognition. As a result, this study concludes proposing that teachers within indigenous education use pedagogical methods that promote the importance of traditional knowledge practices and that enable indigenous students to actively participate in these learning processes.
\end{abstract}

Keywords: Ethnocognition. Indigenous peoples. Education. Medicinal plants.

\footnotetext{
${ }^{1}$ Mestranda em Ciências Ambientais pela Universidade Federal de Rondônia - PGCA/UNIR - Campus de Rolim de Moura. Especialista em Ensino de Ciências e Matemática pelo Instituto Federal de Rondônia - IFRO. ORCID: 0000-0002-3706-9218. E-mail: nauama.diasurui@gmail.com.

2 Doutorando em Sociologia e Antropologia pela Universidade Federal do Rio de Janeiro - PPGSA/IFCS/UFRJ. Mestrado em Desenvolvimento Sustentável pela Universidade de Brasília - CDS/UnB. ORCID: 0000-0002-13906739. E-mail: chsurui09@gmail.com.
} 


\section{Introdução}

Ao longo do tempo os povos indígenas adquiriram uma gama de conhecimento sobre a biodiversidade, saberes esses resultantes de uma relação intrínseca com o ambiente, o que permitiu a sobrevivência desses povos que retiravam da natureza tudo que necessitavam. Entre esses saberes está o domínio do uso de plantas com propriedades medicinais, tanto para tratamento quanto para a prevenção de enfermidades (CARVALHO et al., 2007).

Muitos povos indígenas possuíam avançados sistemas de tratamentos, segundo Luciano (2006), alguns eram capazes de realizar pequenas operações e corrigir e tratar as fraturas ósseas com uso de plantas medicinais, esses saberes e práticas eram transmitidos às novas gerações através da oralidade. $\mathrm{O}$ uso das plantas, além da eficiência terapêutica, possui importante significado cultural, sendo utilizadas por alguns povos de forma mística em rituais de cura, ou seja, na interpretação indígena os usos das plantas perpassam o mundo material e alcançam uma dimensão religiosa e espiritual (ALMEIDA SILVA, 2015).

No entanto, esses conhecimentos correm risco de desaparecerem devido ao processo de colonização e introdução de diferentes culturas antes mesmo dessas plantas serem descobertas pela ciência moderna (ALMEIDA, 2011). São muitos os fatores que contribuem para que ocorram essas rupturas, como por exemplo a inserção dos medicamentos alopáticos através dos postos de saúde instalados nas aldeias, a ação de missionários que adentram as comunidades banindo e demonizando as práticas de curas, e as escolas que não estão preparadas para oferecer uma educação integradora de modo a valorizar o etnoconhecimento (SCANDIUZZI, 2009; SURUÍ, 2015; SANTOS; LIMA, 1991).

Nesse contexto, os estudos etnobotânicos são de grande relevância, pois possibilitam documentar os saberes locais sobre o uso das plantas, contribuindo para a conservação da biodiversidade e fornecendo subsídios para a formulação de políticas públicas adequadas a atender as necessidades básicas dessas populações (COIMBRA JR., 1985; KFFURI, 2008). A etnobotânica também pode ser utilizada como metodologia de ensino capaz de fazer a conexão entre o conhecimento tradicional e científico, preenchendo as lacunas existentes entre ambos e rompendo com os métodos tradicionais de ensino no qual "o educando tinha uma única escolha de ação, qual seja, permanecer sentado, imóvel e em silêncio, podendo dialogar apenas com seus pensamentos" (SIQUEIRA; PEREIRA, 2014, p. 247).

A partir das questões expostas, a proposta deste estudo foi realizar um apanhado dos conhecimentos etnobotânicos com ênfase nas plantas medicinais do povo indígena Paiter Suruí. O modo tradicional de vida dos Paiter Suruí está intimamente ligado à floresta, ainda são muito praticadas entre eles as atividades extrativistas, que são de grande importância para a subsistência da comunidade, o que se coleta é transformado em alimentos, artesanatos, e remédios (BAVARESCO et al., 2011).

As plantas medicinais sempre estiveram presentes na vida da comunidade. Antes do contato com a sociedade não indígena, todas as doenças eram tratadas com remédios da floresta, havia remédio para vários tipos de doenças e fraturas. A comunidade em geral detinha o conhecimento das plantas que era passado oralmente de geração em geração, no entanto, algumas plantas eram de uso exclusivo do Pajé, guia espiritual e curandeiro, responsável por rituais de curas para os casos mais graves (SURUí, 2015).

O contato oficial desse povo com a sociedade nacional ocorreu no ano de 1969, a partir de então a vida dos Paiter Suruí mudou drasticamente. Nos anos que sucederam o contato houve grande migração oriunda das outras regiões do país para o atual estado de Rondônia em busca de terras, estimulado pelo Governo Federal. Com isso, parte do território dos Paiter Suruí foi invadido e devastado para o plantio de cafezais, o que fez parte das plantas medicinais utilizadas 
se perderem, ou ficarem longe das aldeias, dificultando assim o uso dos medicamentos tradicionais. Outro agravante é o distanciamento entre gerações, o aprendizado através do diálogo e observação dos anciãos foi substituído pelo ensino formal nas escolas implantadas nas aldeias, escolas essas que nem sempre dialogam com o conhecimento do povo (MINDLIN, 1985; PAPPIANI; LACERDA, 2016; DIAS; SURUÍ, 2017).

Dessa forma, fica evidente a importância de registrar esses conhecimentos tradicionais desse povo e a partir daí propor metodologias de ensino que promovam a valorização e manutenção de sua cultura tradicional e que atendam aos critérios necessários para uma educação escolar indígena contextualizada e de qualidade. Além do registro da cultura, a pesquisa contribuirá no meio acadêmico como fonte bibliográfica e levará o assunto a conhecimento da população que ainda desconhece o fato de os indígenas serem detentores de tamanho conhecimento.

\subsection{Materiais e procedimentos metodológicos}

O povo indígena Paiter Suruí vive atualmente na terra indígena Sete de Setembro, localizada nos estados de Rondônia e Mato Grosso, em uma área demarcada de 248.146 hectares de floresta amazônica (Figura 1). O território é drenado pelo alto curso do rio Branco (bacia do Roosevelt) e possui três tipos de cobertura vegetal, sendo elas: Floresta Tropical Aberta, sendo esta a mais extensa, Floresta Tropical Densa e área de Tensão Ecológica. O clima da região é Equatorial Continental quente e úmido, com estação seca bem definida (CARDOZO, 2011). As plantas medicinais apresentadas nesta pesquisa são resultantes de estudos in loco realizados na terra indígena por Suruí (2015), Suruí (2017) e Dias e Suruí (2017). Os nomes das plantas são citados apenas no idioma Tupi-Mondé, pois ainda não foi realizada a identificação botânica das mesmas, e ainda não há consenso para que isso aconteça, pois em parte temem que esse conhecimento seja apropriado e utilizado para fins próprios, sem dar ao povo os devidos créditos do saber (METAREILÁ, 2018).

O presente estudo é um artigo de revisão bibliográfica realizado no período de março a agosto de 2020. Durante a pesquisa, foram tomados como base publicações e trabalhos acadêmicos encontrados em banco de dados como o Google Acadêmico, SciELO e Revistas eletrônicas a partir da plataforma Sucupira. A pesquisa foi realizada a partir de palavras-chave como medicina tradicional, plantas medicinais e povos indígenas, etnobotânica indígena, etnobotânica e ensino da ciência e educação escolar indígena. Além dos trabalhos que abordam a temática de um modo geral, utilizou-se também de bibliografias referente aos Paiter Suruí, dando preferência aos autores indígenas.

No primeiro momento foram selecionadas cinquenta bibliografias, após leitura e análise foram escolhidas as que melhor se adequaram à proposta da pesquisa, conforme consta nas referências. As publicações selecionadas para compor o referencial da pesquisa não seguiram um recorte temporal específico, pois há trabalhos relevantes sobre a temática em diferentes períodos, a exemplo dos estudos de Coimbra Jr. (1985) e de Almeida (2018).

Após a seleção do material, realizou-se a leitura e fichamento dos mesmos, ordenando as informações coletadas de acordo com as temáticas específicas, como etnobotânica, educação escolar indígena, medicina tradicional e medicina ocidental, povos indígenas e contato com a sociedade nacional, entre outras. As sugestões de metodologias de ensinos foram feitas a partir das reflexões ocorridas no decorrer da escrita deste trabalho e de experiências relatadas por autores utilizados no decorrer do texto. 


\section{: tear}

Revista de Educação, Ciência e Tecnologia

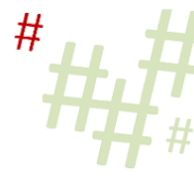

Figura 1 - Localização da Terra Indígena Sete de Setembro

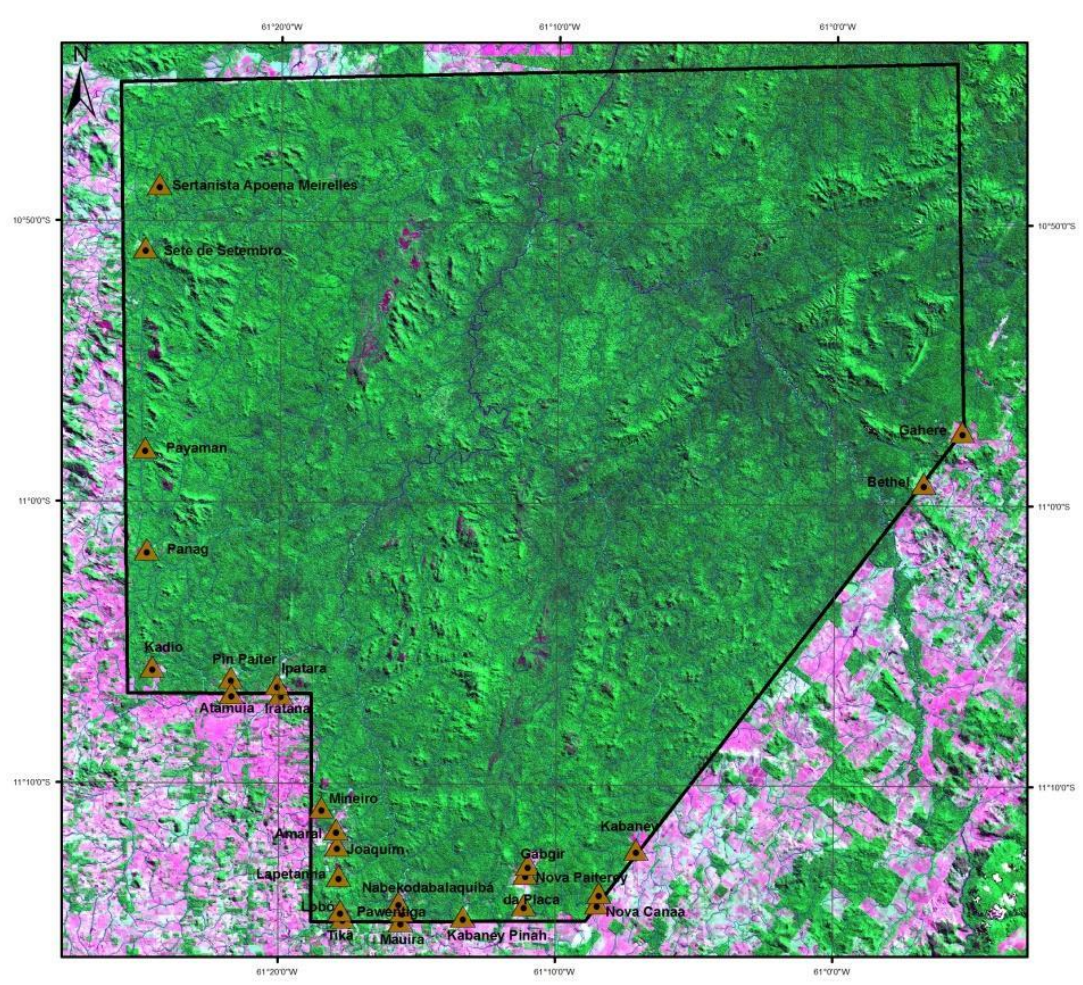

\section{Ecamulo}
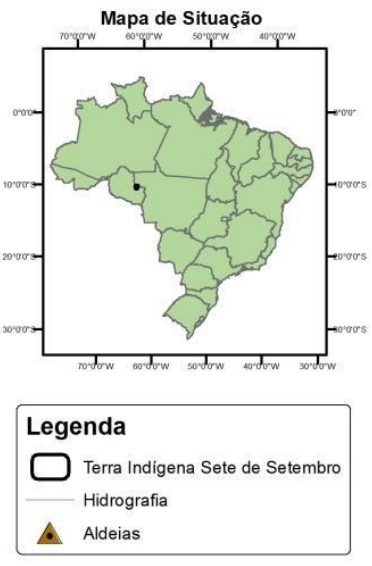

Instituto Nacional de Pesquisas Espaciais
Imagem Landsat $5 \mathrm{TM}-2010$
Orbita 230 Pontos 067 e 068

Projeçāo UTM

Deridiano Central - 63 WG
DATUM SAD69

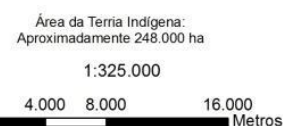

Fonte: ECAM (2010)

A pesquisa teve abordagem qualitativa, pois se preocupa em analisar os dados em seu conteúdo psicossocial considerando a existência de uma dinâmica entre o mundo real e o sujeito, um vínculo entre o mundo objetivo e subjetivo. Neste tipo de pesquisa o sujeito não pode ser traduzido em números por isso não exige utilização de métodos e técnicas estatísticas. Esse tipo de pesquisa oferece contribuições para diferentes campos de estudos como Antropologia, Sociologia, Psicologia e também no campo da Educação e Ensino (PRODANOV; FREITAS, 2013).

\section{Etnobotânica: a relação entre o homem e as plantas}

A etnobotânica foi primeiramente definida por Dr. John William Harshberger, em 1895, como o estudo das plantas usadas pelo povo aborígene ou nativo. Com o tempo, surgiram novas definições, e por volta do século XX passou a ser compreendida como estudo das inter-relações entre os povos primitivos e as plantas (ALBUQUERQUE, 2005).

Atualmente podemos compreender como etnobotânica a ciência que pesquisa a relação entre o homem e as plantas (VIU et al., 2010), ou ainda, segundo Silva e Albuquerque (2004), é a "ciência que estuda as inter-relações entre as sociedades humanas e as plantas".

Com o passar do tempo, várias comunidades acumularam grande conhecimento sobre o uso das plantas, e esse vem sendo transmitido para as novas gerações, chamados de conhecimentos tradicionais. Através dos conhecimentos etnobotânicos podemos verificar o perfil de uma comunidade e seus usos em relação às plantas em seus costumes e peculiaridades (MARTINS et al., 2005). 
A pesquisa etnobotânica abrange recursos alimentícios, pesticidas e contraceptivos, no entanto encontra-se em destaque o uso das plantas medicinais. De acordo com Lindenmaier e Putzke (2011), o conhecimento relacionado às plantas para fins medicinais, em sua maior parte, tem origem a partir dos povos indígenas principalmente em rituais de cura. Muitas dessas plantas foram pesquisadas e atualmente são utilizadas como produtos psicoativos, com isso vêm crescendo o interesse científico em relação aos conhecimentos tradicionais sobre o uso das plantas, pois se percebe que a base empírica em muitos casos tem comprovação científica que estende esse uso à sociedade industrializada (FARNSWORTH, 1988).

Os estudos etnobotânicos podem ser qualitativos ou quantitativos; na abordagem qualitativa não há etapas rígidas a serem seguidas, existe a preocupação em esclarecer como determinada cultura compreende e interpreta as plantas, como se dá e a que níveis chega essa interação (TRIVIÑOS, 1987). A etnobotânica não possui uma estrutura que defina seus métodos e o pesquisador tem livre escolha para usar métodos que alcancem seus objetivos, seja com ênfase quantitativa, qualitativa ou em ambos (ALBUQUERQUE, 2005). É importante que as pesquisas voltadas para este tema valorizem os conhecimentos e medicina tradicional da comunidade, busquem preservar a flora local, ampliar os conhecimentos sobre as propriedades das plantas encontradas e dar suporte a poderes públicos para o desenvolvimento de projetos ambientais e socioeconômicos (SANTOS et al., 1995; ALBUQUERQUE, 2005).

As comunidades tradicionais, de acordo com Rodrigues e Carvalho (2001), possuem vasto conhecimento sobre o ambiente e as plantas. Esses conhecimentos são transmitidos de geração em geração através da oralidade e da prática e estão relacionados com as necessidades da comunidade que os utilizam em seu proveito para a garantia de sua sobrevivência. Assim, percebe-se que a etnobotânica é uma promissora ciência que fornece subsídios para análises de sustentabilidade e dos recursos naturais, principalmente pelo fato de que as comunidades tradicionais são os principais atores sociais que têm uma vida de convivência com a floresta (ALBUQUERQUE, 2005).

\section{1 "Nós Paiter" e o contato}

Os Suruí se autodenominavam Paiter $^{3}$, que significa gente de verdade ou nós mesmos. Antes do contato viviam em uma única e grande aldeia em meio à floresta, caçavam, pescavam e levavam uma vida tranquila, até que em sete de setembro de 1969 ocorreu um fato que mudaria a vida desse povo, o contato oficial com a sociedade nacional que se deu após longas negociações e troca de presentes, repetindo assim a cena de 1500 com a chegada dos europeus em solo brasileiro (MINDLIN, 1985). A história do povo Paiter Suruí é semelhante à história geral dos povos indígenas no Brasil; apesar de terem apenas cinquenta anos de contato oficial com a sociedade nacional, esse povo já sofreu muitos massacres e doenças como os outros grupos indígenas contactados desde 1500.

Durante os primeiros contatos, o povo era cauteloso, apenas os homens se aproximavam dos colonos, enquanto mulheres, crianças e idosos ficavam protegidos na aldeia. Os Paiter Suruí já conheciam o homem branco bem antes do contato oficial, um indígena chamado Waiói conviveu com os brancos no início do século XIX, ao retornar à aldeia ele contava que os não índios tinham hábitos bem diferentes, tinham hora certa para comer, cozinhavam arroz e feijão, tinham panelas, facões e armas de fogo. As experiências de aproximação entre diferentes culturas não foram boas, marcadas por conflitos e mortes entre índios e colonizadores que

\footnotetext{
${ }^{3}$ Após o contato, antropólogos lhes deram o nome Suruí, atualmente preferem ser chamados de Paiter Suruí.
} 
povoavam Rondônia, incentivados pelo governo federal que tinha objetivo de atrair cada vez mais trabalhadores para a região (SURUÍ, 2013).

De acordo com Bavaresco et al. (2011), essa estratégia de ocupação deu-se início em 1920, com a construção da ferrovia Madeira Mamoré, extração da borracha, construção das linhas telegráficas por Candido Rondon e também da BR-364, ligando Cuiabá a Porto Velho. Com isso, os Paiter Suruí, assustados, fugiam cada vez mais para o centro da floresta tentando escapar da invasão dos colonos, mas o cerco se fechou e não havia mais para onde esconder da expansão econômica e agrícola, assim, cederam aos presentes e às tentativas de aproximação ofertadas pela Fundação Nacional do Índio - FUNAI.

Nessa época, a FUNAI recebeu denúncias sobre sérios conflitos entre colonos e indígenas na região e resolveu intervir organizando uma expedição com objetivo de contactar e integrar os Paiter Suruí. Essa expedição era chefiada por Francisco Meirelles (Figura 2). Os indígenas não tinham outra opção a não ser aceitar os presentes e as novas companhias. No entanto, outro fator contribuiu ou forçou essa aproximação, na primeira epidemia entre o povo, praticamente todo povo foi infectado pelo sarampo, doença até então desconhecida por eles, dizimando a população de 5.000 para 250 pessoas. Sem saber o que fazer, os Paiter Suruí procuraram a ajuda dos não índios e isso estreitou ainda mais os vínculos de dependência dos índios para com a sociedade não indígena (METAREILÁ, 2010).

Figura 2 - Primeiro contato oficial do Povo Paiter Suruí em 1969

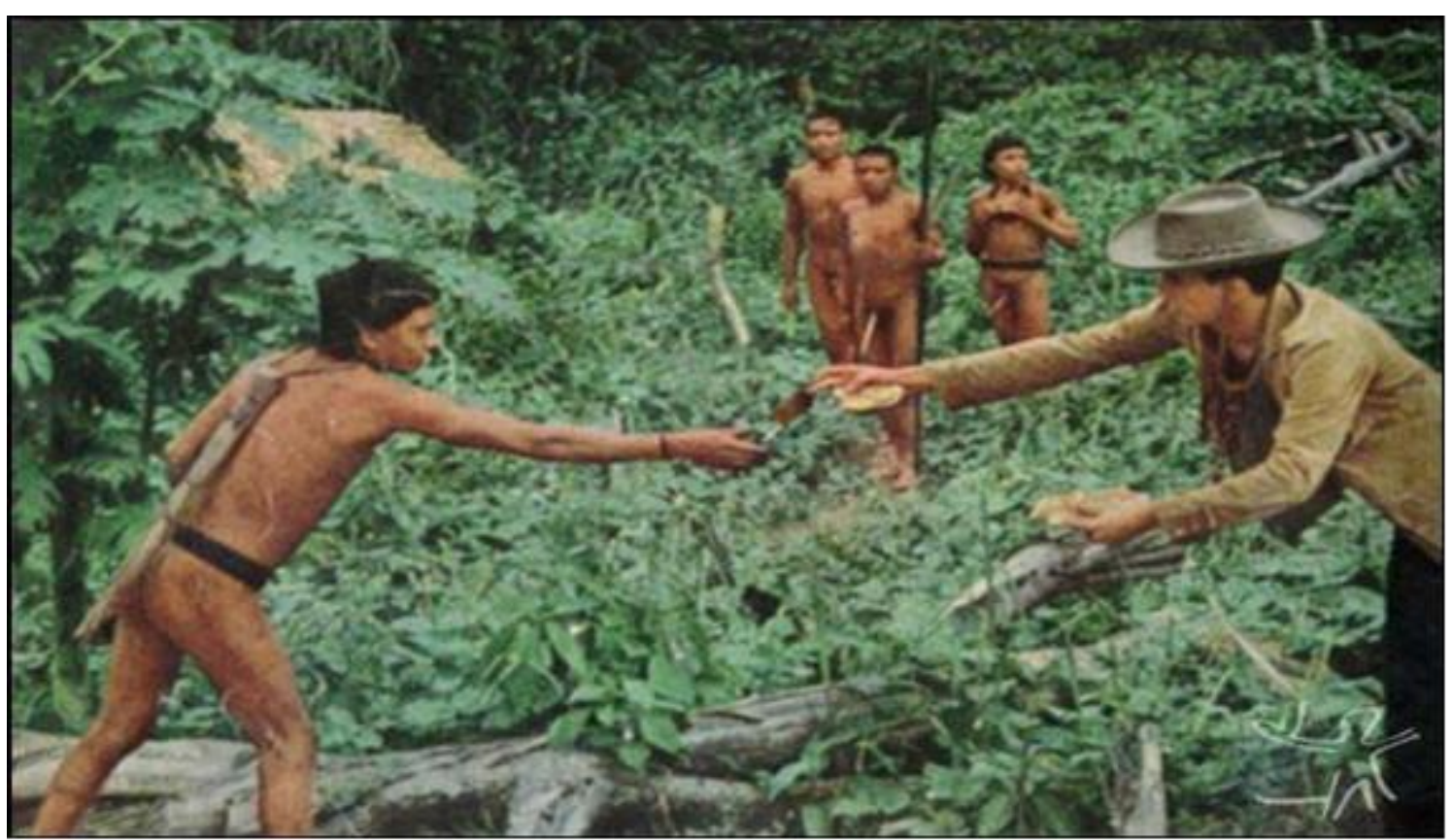

Fonte: Arquivos Metareilá

Nos anos seguintes aumentavam ainda mais o número de colonos vindos de outros estados brasileiros procurando uma vida melhor em Rondônia, com isso, o território dos Paiter Suruí era cada vez mais invadido. O Instituto Nacional de Colonização e Reforma Agrária INCRA, com intuito de colonizar o interior do estado, abriu linhas que facilitaram a ocupação dessas terras pelos colonos que começaram a fazer suas lavouras. No entanto, em sete de setembro de 1976, foi demarcada a terra dos Paiter Suruí, homologada sete anos depois, em 17 de outubro de 1983, através do decreto $\mathrm{n}^{\circ}$ 88867, pelo presidente João Figueiredo, chamada de TISS - Terra Indígena Sete de Setembro, localizada entre Rondônia e Mato Grosso, em uma 
área de 248.146 hectares. Essa era uma área pequena, comparada às imensas terras habitadas no passado, como mostra a fala de Natim Suruí (BAVARESCO et al., 2011 p. 11).

\begin{abstract}
Nosso cemitério é fora da área e, onde nasci agora é área de fazenda. A parte da floresta onde tinha ponto da pesca, mel, caça, frutas, foi tudo reduzido. A nossa área mesmo, a maior parte ficou fora da área demarcada. Perdemos muita coisa e hoje em dia estamos cuidando desse pequeno espaço.
\end{abstract}

Após a demarcação e homologação de suas terras, o povo Paiter Suruí resolveu lutar agora pela sua desocupação, já que havia mais de mil famílias de colonos fixadas na então Terra Indígena Sete de Setembro. Com isso, deu-se início a intensos conflitos para essa reintegração de posse com sangrenta batalha, de um lado os indígenas com seus arcos e flechas e do outro os colonos com suas armas de fogo, segundo Suruí (2013), houve muitas mortes de ambos os lados, uma verdadeira guerra civil. Com isso, a Força Nacional e a Cruz Vermelha foram convocadas para tentar resolver o problema, esse fato ficou conhecido nacionalmente na época devido à gravidade do acontecido.

Depois de intenso conflito, os Paiter Suruí retomaram a posse de suas terras e agora precisavam protegê-las de novas invasões, já que estava cercada de colonos. Então a aldeia foi dividida, as famílias migraram para os finais das linhas criando novas aldeias para facilitar a proteção das fronteiras, que é uma área mais vulnerável a invasões de colonos e madeireiros. Atualmente, são aproximadamente 27 aldeias com uma população de aproximadamente 1.300 indígenas. Além de proteger a terra, os indígenas também se apossaram das lavouras de café deixadas pelos colonos. A partir de 1980, a situação fundiária foi se definindo e os limites da terra indígena sendo respeitados pelos migrantes colonos (METAREILA, 2010).

\title{
2.2 Etnobotânica no dia a dia dos Paiter Suruí, com ênfase nas plantas medicinais
}

Considerando a etnobotânica como a ciência que estuda a relação entre homens e plantas, logo se percebe que os povos indígenas possuem um vasto conhecimento etnobotânico pela sua intensa relação de dependência com a natureza. Não diferente, o povo Paiter Suruí vem acumulando uma gama de saberes relacionados às plantas, pois, antes do contato com os yaraey (não indígenas), o povo vivia na floresta, em grandes malocas com as portas voltadas para o sol. Havia um grande pátio para a socialização e várias malocas de reclusão que eram utilizadas para parto, pessoas de luto, menstruação ou iniciação a pajelança. Nas malocas não havia muitos objetos, além das redes, panelas de barro, esteiras e cestos de palha, não se guardava muitos alimentos, com estoque para no máximo três dias, geralmente caças, peixes e beijus $^{4}$, que defumavam nas lareiras e algumas frutas (SURUÍ, 2015).

$\mathrm{O}$ ambiente era no geral alegre e afetuoso, todos compartilhavam os alimentos e comiam juntos quando dava vontade, sem hora marcada. Não havia uma rígida rotina, mas geralmente acordavam cedo e iam banhar-se no rio. Após, comiam o que tinha armazenado e iam para as roças para renovar seu estoque. Também colhiam banana e mamão pelo caminho, geralmente em grupos. Não gostam de estar sós, pois temem o espírito da floresta. As mulheres eram responsáveis pela colheita de cará, mandioca e batata doce, e os homens se encarregavam do plantio e caça (MIDLIN, 1985).

\footnotetext{
${ }^{4}$ Alimento tipicamente de origem indígena feita com a tapioca, que ao ser espalhada em uma chapa aquecida coagula-se e vira um tipo de panqueca ou crepe seco.
} 
As caçadas duravam horas, às vezes dias na mata, não se levava comida, a não ser alguns beijus, não poderiam carregar nenhum peso e deveriam ter resistência, no retorno os caçadores eram recebidos com alegria, traziam a caça e a distribuíam entre a comunidade, as de melhor qualidade eram tatu e queixada. As crianças aprendiam com os adultos nas atividades cotidianas, imitando e aprendendo, os mais velhos transmitiam seus conhecimentos através da oralidade, contavam as histórias e cantavam o canto do seu povo (GHATAG SURUÍ apud PAPPIANI; LACERDA, 2016, p. 54).

Ghatag (2016) relata ainda que todos gostavam de pescar, e assim faziam a qualquer momento, com arco e flecha ou timbó, uma espécie de cipó venenoso que torciam e batiam na água em riachos represados por tronco, a água escurecia e os peixes que ali estavam morriam e eram recolhidos pela comunidade; a única preocupação era esta: buscar comida.

Os Paiter Suruí retiravam da floresta tudo o que precisavam, as casas eram construídas de palha, as flechas de taquara, tinta de jenipapo e pelo de porco do mato, para colares pulseiras e anéis, utilizavam-se coquinhos de tucumã, casco de tatu, plumas de arara para os cocares, todos faziam viagens mata adentro em busca desses objetos e alimentos, mel, castanhas, cacau e outros inúmeros frutos que a floresta oferecia (MINDLIN, 1985).

Eram feitos muitos enfeites, colares de cocos e sementes, flechas de taquara e panelas de barro; esses artefatos estavam presentes no cotidiano dos Paiter Suruí e nas festas se intensificavam ainda mais. Os Paiter Suruí eram alegres e festivos, duas importantes festas eram o Mapimaí, festa para celebrar a colheita e a criação do mundo, e o Hô-êi-ê-tê, festa convocada para cura e prevenção de doenças (SURUí, 2015, p. 22).

Como mencionado anteriormente, um dos fatores que forçaram a aproximação entre os Paiter Suruí e os yaraey foram as doenças, "doenças de branco" que dizimaram a população, gripe, sarampo e tuberculose, uma série de males até então por eles desconhecidos. O povo Paiter Suruí, não diferente de outras comunidades indígenas, possui um vasto conhecimento sobre a utilização da floresta para fins medicinais, mas como tratar uma doença desconhecida?

Antes do contato com os yaraey a questão da saúde era bem diferente, como relata Itabira Suruí:

No Passado vivíamos com muita tranquilidade, sem preocupação com a saúde. Nós conseguíamos manter nossa saúde com a pajelança, com a espiritualidade, quem mantinha nossa saúde era o pajé, usando os espíritos dos rios, do céu, do mato. O pajé mantinha a população Suruí com Saúde, ao mesmo tempo conhecíamos as raízes para remédio, no mato não era qualquer árvore (BAVARESCO et al., 2011, p. 12).

Marimop Suruí afirma que a forma de vida da comunidade também interferia diretamente na saúde, pois viviam de forma natural, muito diferente de hoje. Para ele, a vida era mais tranquila e as práticas culturais eram presentes (BAVARESCO et al., 2011).

Sempre quando questionados sobre a vida anterior ao contato, os Suruí enfatizam a questão da saúde. Anine Suruí relata que a vida era muito boa, viviam bem e com muita saúde, a alimentação era saudável, extraída da floresta, havia muitas frutas, chicha, bebida típica Paiter Suruí, batata doce, milho, mandioca e muita caça, não havia doenças. Ele afirma que doenças como tuberculose, gripe, malária eram desconhecidas (PAPPIANI; LACERDA, 2016).

Se as doenças citadas anteriormente não faziam parte da rotina dos Paiter, que males os acometia e o que os ocasionava? Observando a Tabela 1 referente às plantas medicinais utilizadas pelos Paiter Suruí, pode-se observar que as doenças presentes eram em sua maioria 
males intestinais, como diarreia, e que o que predominava eram ferimentos, picadas de cobras e mosquito, naturais para a vida em floresta. Acreditava-se que qualquer desses males anteriormente citados era proveniente de maus espíritos, e nesse caso era de responsabilidade do pajé acalmá-los (MINDLIN, 1985).

Suruí (2015) fez um sucinto estudo sobre os conhecimentos das plantas medicinais utilizadas por seu povo. Ele relata que essas plantas são de grande importância para a comunidade, principalmente os mais velhos. Existe todo um processo para a utilização dessas plantas, envolvendo rituais e espiritualidade, um exemplo disso é a prática de arrancar a planta, tirar-lhe as folhas e plantá-la novamente. Segundo a crença, isso serviria para saber se o doente seria curado, se a planta nascesse novamente haveria cura, ao contrário, o doente não sobreviveria. As árvores e cipós cuja casca e/ou folhas eram extraídas deveriam ser tratadas com respeito para que não morressem, era raspada com cuidado e em um lugar específico para não causar dano à planta.

As mulheres Paiter Suruí possuem maior habilidade nas práticas cotidianas da medicina tradicional, são elas que geralmente colhem e preparam o remédio específico para cada doença. Segundo Dias et al. (2019, p. 40 ), "essa habilidade feminina dentro da família é muito útil e eficaz, resolvendo muitos dos problemas de saúde enfrentados pela comunidade, como a diarreia, febre, dores, tosse, vermes, falta de apetite, anemia, fraqueza, infertilidade, e também para escolha do sexo do neném”.

A preocupação com a saúde e bem estar do indivíduo Paiter Suruí iniciava ainda na gravidez. Durante a gestação, a mulher se prepara para o momento do nascimento da criança. A anciã da família deve preparar a grávida para o momento do parto, buscando, preparando e aplicando os remédios. Quando todas as práticas eram seguidas corretamente desde a gestação, a pessoa Paiter Suruí se forma forte e saudável, a transição para a velhice acontece de forma menos traumática.

\footnotetext{
Alguns desses medicamentos são feitos utilizando-se as folhas de itir megãi, pãrah sop e guerejung, e podem ser ministrados de três formas: uso tópico na barriga, no banho, ou ingerindo-se por via oral e podem ser usados durante toda a gravidez. Parã h epih esop (buriti) é boa também beber e para a gestante tomar banho, amassando as folhas novas de uma muda pequena da palmeira, retirando um sabão liso e escorregadio que vai ajudar a criança a nascer com facilidade na hora do parto (DIAS et al, 2019, p. 46).
}

A Vida cotidiana dos Paiter os expunha a alguns riscos. Nas longas andanças na floresta, acidentes com serpentes venenosas eram recorrentes, nesse caso, recorriam ao Makop, uma erva cujas folhas eram espremidas sobre o ferimento, essa planta possui propriedades antiofídicas e anestésicas sendo utilizada também em picadas de insetos. Fraturas também eram comuns, principalmente na derrubada para plantio do roçado, quando eram atingidos por galhos. Como remédio utilizava-se Gãpikãrey- $A$, casca dessa árvore juntamente com uma espécie de cupim presente na mesma e aplicava-se no local em forma de cataplasma, resultando numa rápida regeneração óssea (SURUÍ, 2015).

A utilização de algumas plantas estavam para além das práticas de cura, envolviam a espiritualidade, como o Ipagaríh, um remédio muito poderoso, feito com várias ervas de gosto muito amargo, era utilizado em ritual de purificação como tratamento espiritual contra os perigos e ameaças do mundo sobrenatural. De forma semelhante, utilizavam Penõb (urtiga) em ritual chamado Penõb Areh Eweh (festa de passar urtiga), na ocasião os anciãos da comunidade passam a urtiga no corpo dos demais, inclusive crianças. Esse ritual traz purificação para o 
corpo, afasta os maus espíritos, dá coragem para ser um bom guerreiro, além de significar um gesto de gratidão pelo início da colheita (PAPPIANI; LACERDA, 2016).

A tabela a seguir foi elaborada a partir de pesquisa in loco realizada por Suruí (2015, p. 23-27) e Paibiniga Suruí (2017, p. 27-38), contendo algumas das plantas medicinais utilizadas pelo povo Paiter, bem como sua indicação e forma de uso.

Tabela 1 - Informações sobre uso de plantas medicinais entre os Paiter Suruí

\begin{tabular}{|c|c|c|c|}
\hline $\begin{array}{l}\text { Nome da planta } \\
\text { (em Tupi Mondé) }\end{array}$ & $\begin{array}{l}\text { Para que serve esse } \\
\text { remédio? }\end{array}$ & $\begin{array}{l}\text { Qual a } \\
\text { parte } \\
\text { coletada? }\end{array}$ & Como é usado para curar? \\
\hline Anaragoia & Deixar o cabelo liso & Folha & Passar o sumo da folha no cabelo. \\
\hline Gãpikãrey & $\begin{array}{l}\text { Quando quebra o } \\
\text { osso }\end{array}$ & Casca & $\begin{array}{l}\text { Retira a casca e o cupim da } \\
\text { casca, molha e coloca no local da } \\
\text { fratura como se fosse um gesso. }\end{array}$ \\
\hline Garauw & $\begin{array}{l}\text { Cura dor de dente e } \\
\text { dor no corpo }\end{array}$ & Casca & $\begin{array}{c}\text { Molha na água e passa no corpo } \\
\text { ou pinga no dente. }\end{array}$ \\
\hline $\begin{array}{l}\text { Gaweipagah / } \\
\text { Gabeypagah }\end{array}$ & $\begin{array}{c}\text { Cura diarreia, dá } \\
\text { coragem pra caçar, } \\
\text { plantar e enfrentar os } \\
\text { perigos }\end{array}$ & Casca & Coloca na água e depois bebe. \\
\hline $\begin{array}{l}\text { Geroxakup- } \\
\text { Eypagah }\end{array}$ & $\begin{array}{l}\text { Feridas difíceis de } \\
\text { cicatrizar }\end{array}$ & Casca & $\begin{array}{l}\text { Raspa a casca, espreme em cima } \\
\text { do ferimento. }\end{array}$ \\
\hline Goniõ & Feridas na boca & Seiva & $\begin{array}{c}\text { Retira a casca e pinga a seiva no } \\
\text { local da inflamação. }\end{array}$ \\
\hline Guerih & Agitação e insônia & Folha & Amassa a folha na água e bebe. \\
\hline Guerinhõ & Fraquezas e tonturas & Folha & Amassa a folha na água e bebe. \\
\hline Inileialavarim & $\begin{array}{c}\text { Serve como } \\
\text { tranquilizante }\end{array}$ & Folha & Passa as folhas no corpo de leve. \\
\hline Itxirmegãim & $\begin{array}{c}\text { Para facilitar o parto } \\
\text { e diminuir a } \\
\text { menstruação } \\
\end{array}$ & Folha & $\begin{array}{c}\text { Toma o sumo amassado em água } \\
\text { e passa no corpo. }\end{array}$ \\
\hline Matxahk & $\begin{array}{l}\text { Má digestão e } \\
\text { conjuntivite }\end{array}$ & Casca & $\begin{array}{c}\text { Para má digestão: raspa a casca e } \\
\text { mistura com água e toma em } \\
\text { grande quantidade até provocar } \\
\text { vômito. Para conjuntivite: lava o } \\
\text { olho com a água que colocou a } \\
\text { casca. }\end{array}$ \\
\hline Mokop & $\begin{array}{c}\text { Anestésico para } \\
\text { picadas de cobra e } \\
\text { insetos } \\
\end{array}$ & Folha & $\begin{array}{l}\text { Espremer o miolo da folha em } \\
\text { cima do ferimento. }\end{array}$ \\
\hline
\end{tabular}


Revista de Educação, Ciência e Tecnologia

\begin{tabular}{|c|c|c|c|}
\hline MoraTapoh & $\begin{array}{l}\text { Fraqueza, tontura e } \\
\text { males estomacais }\end{array}$ & Casca & $\begin{array}{l}\text { Retira a casca e coloca de molho } \\
\text { por vários dias, depois usa a água } \\
\text { para tomar banhos e ingerir até o } \\
\text { vômito para limpar o intestino. }\end{array}$ \\
\hline Nhegarah & $\begin{array}{l}\text { Tosse, rouquidão e } \\
\text { gripe }\end{array}$ & Casca & $\begin{array}{l}\text { Deixa de molho, depois toma } \\
\text { com água e passa no peito para } \\
\text { tosse e expectorar. }\end{array}$ \\
\hline NheNhêpagah & $\begin{array}{l}\text { Diarreia (dá pra } \\
\text { criança antes de } \\
\text { comer certos tipos de } \\
\text { peixe) }\end{array}$ & Folha & $\begin{array}{l}\text { Tomar o sumo da folha amassada } \\
\text { com água. }\end{array}$ \\
\hline $\begin{array}{c}\text { Pãgaley/ } \\
\text { Pangoragey }\end{array}$ & $\begin{array}{l}\text { Tosse, diarreia, falta } \\
\text { de apetite e serve } \\
\text { como vitamina }\end{array}$ & Folha & $\begin{array}{l}\text { Amassar na água e tomar em } \\
\text { todos os casos. }\end{array}$ \\
\hline Paixamekorah & $\begin{array}{l}\text { Dores no corpo e } \\
\text { juntas/ reumatismo/ } \\
\text { diarreia/dor no } \\
\text { ouvido/gripe }\end{array}$ & $\begin{array}{l}\text { Casca e } \\
\text { Folha }\end{array}$ & $\begin{array}{l}\text { Para diarreia, tomar a folha } \\
\text { macerada na água; para dores, } \\
\text { esquentar a casca raspada e } \\
\text { aplicar compressa no local da } \\
\text { dor; cheirar a casca para gripe; e } \\
\text { por a folha no ouvido para dor. }\end{array}$ \\
\hline Pexoey Pabewar & $\begin{array}{l}\text { Má digestão/ barriga } \\
\text { inchada/dor no corpo/ } \\
\text { lesões e reumatismo }\end{array}$ & Casca & $\begin{array}{l}\text { É raspada a casca e coloca em } \\
\text { molho na água quente, tomar o } \\
\text { chá em grande quantidade até } \\
\text { vomitar, e tomar banho com a } \\
\text { mesma água e fazer compressas } \\
\text { para aliviar as dores. }\end{array}$ \\
\hline Sãy & $\begin{array}{c}\text { Tosse, Febre, } \\
\text { anestésico para dor de } \\
\text { dente e reumatismo }\end{array}$ & Casca & $\begin{array}{l}\text { Para febre e reumatismo tomar } \\
\text { banho com a casca; mastigar a } \\
\text { casca para dor de dente; passar } \\
\text { no local do machucado para } \\
\text { aliviar a dor; passar no tórax para } \\
\text { aliviar a tosse. }\end{array}$ \\
\hline $\begin{array}{c}\text { Sobagey Xabor } \\
\text { Gãp }\end{array}$ & Para ter filho homem & Folha & Fazer banho de assento na folha. \\
\hline
\end{tabular}

Fonte: Adaptado de Alexandre Suruí, (2015, p. 20-28); Paibiniga Suruí (2017, p. 27-38).

O povo Paiter Suruí, além de tratar as doenças com as plantas medicinais, também possuía formas de prevenção para as mesmas, que incluía rigorosas dietas alimentares e reclusão. Durante a gravidez, a mulher não comia amendoim, considerado abortivo para elas, no entanto, deveria comer muita castanha e milho para a criança nascer forte. Quando o neném nascia, a mãe não podia comer amendoim e milho, pois esses alimentos poderiam fazer mal ao bebê ao ser amamentado. Todas as dietas e proibições mencionadas foram descritas por Mindlin (1985, p. 66). 
Os conhecimentos sobre as plantas eram transmitidos oralmente de pai para filho, nos casos mais graves era chamado o wãwã (Pajé). Este possuía um conhecimento mais avançado sobre as plantas medicinais, pois dedicava sua vida completamente em aprender e aprimorar seus saberes para cura, e também contava com a ajuda dos espíritos durante os rituais de cura.

O mais importante dos rituais de cura era o Hô-êi-ê-te, considerada uma festa devido à grandiosidade. A antropóloga Betty Mindlin (1985) teve a oportunidade de assistir a última destas festas, em um período turbulento de pós-contato. A autora conta que essa festa sagrada era realizada para a cura e prevenção de doenças, os espíritos vinham da floresta para a cerimônia, que durava cinco dias e noites.

O Pajé comandava a festa, puxando o canto com seu bastão de taquara enfeitado com plumas vermelhas o "narai". Ao som do canto, a dança era realizada em duas rodas, em uma ficavam o pajé, alguns homens que seguravam taquaras enormes com palhas nas pontas onde eram incorporados os espíritos e casais que dançavam abraçados, a outra roda era a dos que tocavam as flautas. As crianças menores não participavam da festa, pois não suportariam a presença sobrenatural. Eram invocados Goanei, espíritos das águas, e Goarei, espíritos do céu, que desciam sobre a aldeia trazendo cantos e histórias, cantados e contadas pelo pajé, o intermediador. Assim, através dessa intensa relação com as plantas e com a natureza de um modo geral o povo se mantinha vivo e saudável.

\subsection{Impactos do contato sobre os conhecimentos etnobotânicos}

O contato provocou intensas mudanças na vida dos Paiter, agora denominados Suruí pela FUNAI. Mindlin (1985, p. 100) afirma que basta olhar para a forma que fazem a coleta dos cocos e das sementes para artesanatos, não há mais prazer em fabricá-los lentamente, sem pressa, cuidando de cada detalhe, hoje eles possuem valor monetário, precisam fabricar cada vez em quantidades maiores. Há muito desejo pelo dinheiro e por mais variados utensílios, roupas, e até chuteiras de futebol.

Além das roupas, é necessária a munição, a maioria não utiliza mais o arco e flechas feitos de taquara em suas caças, para a pesca o cipó timbó deu lugar a anzóis, para as redes, o fiar de algodão deu lugar às cordas industrializadas. Bicicletas, motos, enfim, com tamanha proximidade (forçada) com a cidade, devido à perda da maior parte de seu território, é impossível imaginar que continuariam mantendo as suas tradições e cultura.

Para financiar esse consumo, atualmente, cada família utiliza-se de meios diferentes, não há mais coletividade, alguns vendem madeira, outros fazem roça, alguns coletam castanha e assim vão sobrevivendo. A renda dos Paiter Suruí atualmente é proveniente em sua maior parte da agricultura, extração da madeira, arrendamento de terras e programas sociais como Bolsa Família. Essa nova forma de organização gera desigualdade, causando inclusive conflitos internos, as roças não são mais coletivas, cada um só pode usufruir de sua própria colheita, e o excedente é vendido, não há mais tempo para a socialização, agora são horas de trabalho árduo para conseguir produzir para a comercialização (SURUí, 2015).

Em relação à saúde e às plantas medicinais, infelizmente hoje não se realiza mais o Hôêi-ê-te, nem há mais pajés, com a chegada das igrejas nas aldeias as realizações das práticas culturais deram lugar ao medo do castigo de Palob (ser criador), como mostra a fala de Alexandre Suruí:

Hoje não temos Pajé na nossa aldeia por motivo da chegada da igreja, o Pastor proibiu, deu medo a ele dizendo que esse trabalho do Pajé é do DIABO, não é pertencente a 
DEUS, isso não leva as pessoas ao CÉU, isso pode levar ao inferno, e deu medo (SURUÍ, 2015, p. 20).

Atualmente sobraram apenas alguns resquícios da medicina tradicional Paiter Suruí que se deve à utilização de algumas plantas medicinais, não em sua totalidade como no passado. Os mais velhos que são detentores do conhecimento são os que fazem maior uso, em contrapartida, os jovens não se interessam por essa prática, utilizando em sua maioria os "remédios de farmácia", não aprendendo com a experiência dos mais velhos (SURUí, 2015, p. 21).

\subsection{A Importância da educação escolar indígena para a manutenção do etnoconhecimento}

Ainda há a equivocada ideia de que os povos indígenas não possuem em sua forma tradicional nenhuma forma de educação. A educação é definida como processo de socialização de cada indivíduo, isso ocorre em toda e qualquer cultura, é a influência de um ser humano para o outro a fim de que aprenda a desempenhar seu papel no contexto social, econômico, político e cultural em uma determinada sociedade (HUBERT, 1976).

Assim, a educação indígena é um processo próprio de produção e transmissão de conhecimento, esses saberes são transmitidos através da oralidade de geração a geração, permitindo assim a formação de diferentes habilidades na comunidade. Há músicos, artesãos, lavradores, caçadores e pescadores. Culturalmente não há a necessidade da figura do professor, pois as crianças aprendem através da observação, vendo os pais, avós, tios, e vão reproduzindo os comportamentos, adquirindo valores e se inserindo na sociedade.

A educação escolar por outro lado, é o processo de transmissão de conhecimento trazido pelos colonizadores, por muito tempo os povos indígenas tiveram repulsa a este tipo de ensino, para eles tratava-se de uma forma de aculturação. Esse sentimento é má herança dos primórdios da colonização, nos quais os povos indígenas eram retirados de suas aldeias e obrigados a passarem pelo processo de catequização, um dos primeiros ensinos da época. Freire (2004) reforça a ideia dos impactos desse período nas culturas indígenas afirmando que quando a escola foi implantada em área indígena, as línguas, a tradição oral, o saber e a arte dos povos indígenas foram discriminados e excluídos da sala de aula.

A função da escola era fazer com que estudantes indígenas desaprendessem suas culturas e deixassem de ser indígenas. Historicamente, a escola pode ter sido o instrumento de execução de uma política que contribuiu para a extinção de mais de mil línguas. Fato é que ainda hoje a escola continua a ignorar a pedagogia tradicional, contribuindo assim cada vez mais ao enfraquecimento da cultura (LUCIANO, 2006). O autor diz ainda que as principais críticas dos povos indígenas ao sistema de ensino atual é a reprodução dos modelos de ensino da sociedade nacional nas comunidades indígenas. Os currículos, diretrizes e programas não se adequam à realidade dos povos indígenas; os materiais didático-pedagógicos são ineficientes e insuficientes; não há adequada supervisão pedagógica nas escolas; as atividades educacionais são prejudicadas pela falta de professores na comunidade devido à ausência de moradias, transporte e alimentação. Os professores não indígenas têm dificuldade de desenvolver seus trabalhos, principalmente o processo de alfabetização, devido à barreira linguística (SCANDIUZZI, 2009).

Os movimentos indígenas a partir da década de 1980 vêm tomando iniciativas nas escolas e comunidades a fim de aquecer o debate sobre o modelo ideal de escola para a comunidade, chamada escola indígena específica com linhas políticas ligadas às questões 
pedagógicas culturais. Hoje há certas conquistas, como a Resolução CNE n. 05/2012, que institui as Diretrizes Nacionais para a Educação Básica na Educação Escolar Indígena.

\begin{abstract}
Art. $4^{\circ}$ Constituem elementos básicos para a organização, a estrutura e o funcionamento da escola indígena: I - a centralidade do território para o bem viver dos povos indígenas e para seus processos formativos e, portanto, a localização das escolas em terras habitadas por comunidades indígenas, ainda que se estendam por territórios de diversos Estados ou Municípios contíguos; II - a importância das línguas indígenas e dos registros linguísticos específicos do português para o ensino ministrado nas línguas maternas das comunidades indígenas, como uma das formas de preservação da realidade sociolinguística de cada povo; III - a organização escolar própria, nos termos detalhados nesta Resolução; IV - a exclusividade do atendimento a comunidades indígenas por parte de professores indígenas oriundos da respectiva comunidade. Parágrafo único: A escola indígena será criada em atendimento à reivindicação ou por iniciativa da comunidade interessada, ou com a anuência da mesma, respeitadas suas formas de representação (BRASIL, 2012).
\end{abstract}

A educação escolar indígena é o processo misto de transmissão de conhecimento (não indígenas e indígenas) na escola. Quando se fala em educação escolar indígena, trata-se se de um ambiente escolar apropriado às comunidades indígenas, nos quais seus conhecimentos são valorizados e seu projeto cultural reforçado ao mesmo tempo que os prepara para as novas demandas que surgiram a partir do contato.

É importante registrar a grande contribuição do Movimento dos Professores Indígenas do Amazonas, Roraima e Acre (COPIAR) atual Conselho dos Professores Indígenas da Amazônia (COPIAM). Esse grupo se reúne anualmente desde 1988 para discutir os problemas e propor soluções para as escolas indígenas. Parte significativa desse trabalho foi a elaboração da "Declaração de Princípios" durante o IV Encontro. Esse documento elenca 15 pontos com proposta de política educacional a fim de subsidiar e fortalecer a escola indígena em todos os níveis de ensino.

As propostas da Declaração de Princípios são:

1. As escolas indígenas deverão ter currículos e regimentos específicos, elaborados pelos professores indígenas, juntamente com suas comunidades, lideranças, organizações e assessorias.

2. As comunidades indígenas devem, juntamente com os professores e as organizações, indicar a direção e a supervisão das escolas.

3. As escolas indígenas deverão valorizar culturas, línguas e tradições de seus povos.

4. É garantida aos professores, comunidades e organizações indígenas a participação paritária em todas as instâncias - consultivas e deliberativas - de órgãos públicos governamentais responsáveis pela educação escolar indígena.

5. É garantida aos professores indígenas uma formação específica, atividades de reciclagem e capacitação periódica para o seu aprimoramento profissional.

6. É garantida a isonomia salarial entre professores índios e não índios.

7. É garantida a continuidade escolar em todos os níveis aos alunos das escolas indígenas.

8. As escolas indígenas deverão integrar a saúde em seus currículos, promovendo a pesquisa da medicina indígena e o uso correto dos medicamentos alopáticos.

9. O Estado deverá equipar as escolas com laboratórios, onde os alunos possam ser treinados para desempenhar papel esclarecedor junto às comunidades no sentido de prevenir e cuidar da saúde.

10. As escolas indígenas serão criativas, promovendo o fortalecimento das artes como formas de expressão de seus povos. 
11. É garantido o uso das línguas indígenas e dos processos próprios de aprendizagem nas escolas indígenas.

12. As escolas indígenas deverão atuar junto às comunidades na defesa, na conservação, na preservação e na proteção de seus territórios.

13. Nas escolas dos não índios será corretamente tratada e veiculada a história e a cultura dos povos indígenas brasileiros, a fim de acabar com os preconceitos e o racismo.

14. Os municípios, os estados e a União devem garantir a educação escolar específica às comunidades indígenas, reconhecendo oficialmente suas escolas indígenas de acordo com a Constituição Federal.

15. Deve ser garantida uma Coordenação Nacional de educação escolar indígena, interinstitucional, com a participação paritária de representantes dos professores indígenas (LUCIANO, 2006, p. 144).

Essa proposta de educação diferenciada cumpre a função e chama a atenção da sociedade brasileira de modo geral para a necessidade de repensar o papel da escola e auxilia na desconstrução da ideia de que os indígenas não podem assegurar sua sobrevivência, necessitando dos não índios para ensiná-los. Dias e Suruí (2017, p. 51) reforçam a necessidade dessa educação diferenciada afirmando que "a educação que queremos deveria partir do princípio da junção de ambos os entendimentos de educação, do Paiter Suruí e do EstadoNação, pois não é possível o povo indígena manter sua identidade cultural apenas se adequando a uma parte do conhecimento".

Nesse sentido, Siqueira (2012, p. 3) afirma "que a escola é um espaço multicultural e que tem, nesta perspectiva, o compromisso de aproveitar tais saberes ou culturas em seu currículo, em quaisquer atividades didático-pedagógicas desenvolvidas em seu interior”. Em seu artigo, o autor aponta atividades possíveis de serem realizadas de forma interdisciplinar e multicultural na educação básica com enfoque na etnobiologia. Siqueira (2012) afirma ainda que os conteúdos devem ser apresentados aos alunos, após deve ser promovida uma discussão para que os mesmos expressem seus conhecimentos sobre o assunto, e, no caso das plantas medicinais, o autor sugere a ida a campo "para que estes observem o cultivo das mesmas, o armazenamento das mesmas, as fontes dos saberes dos entrevistados entre outros" (SIQUEIRA, 2012, p. 4).

Sob o aporte da etnobotânica abre-se um leque de possibilidades a ser explorado pelos professores de escolas indígenas no ensino da biologia. Para aprender sobre os ecossistemas pode se apresentar as características dos principais ecossistemas brasileiros e pedir que os alunos identifiquem a qual ecossistema pertence o ambiente em que ele vive, e mostrar que outros povos, que vivem em outros ecossistemas, utilizam outros tipos de plantas para suprirem suas necessidades (ALMEIDA, 2018).

A criação de exsicatas, que é uma amostra de plantas seca e prensada, também é uma possibilidade a ser exploradas pelos professores no ensino da biologia que valoriza e os conhecimentos etnobotânicos dos alunos. Cada aluno deve consultar um ancião da família sobre uma planta medicinal, indicação e forma de uso, uma amostra deve ser coletada e levada para ser prensada. A partir das plantas coletadas é possível trabalhar diversos conteúdos, como partes das plantas, grupos, tipo de reprodução, as Gimnospermas, Angiospermas (ALMEIDA, 2018). Outra proposta que pode auxiliar na retomada do uso das plantas medicinais pelos mais jovens é a construção de hortos medicinais. De acordo com Kovalski e Obara (2013), esse espaço pode ser utilizado de forma didática e pedagógica permitindo o contato prático com as plantas e servindo como ambiente de diálogo, resgate e valorização do conhecimento tradicional sobre as plantas medicinais. 
Trabalhar com a temática das plantas medicinais nas escolas permite a associação de diversos saberes, e através desse diálogo entre as diferentes formas de conhecimento chegando assim a um aprendizado significativo sobre o tema (KOVALSKI; OBARA, 2013). Essa interação valoriza a cultura da comunidade, auxilia no aprendizado, o professor pode explorar inúmeros recursos existentes na comunidade para que suas aulas promovam uma real educação escolar indígena. Esses recursos podem ser explorados não apenas no ensino da biologia, mas também na matemática, história e outras, pois os povos indígenas possuem um amplo e variado conhecimento a ser explorado. Dessa forma, utilizar a etnobotânica como ferramenta de ensino possibilita "além de resgatar, valorizar, tende a preservar os conhecimentos tradicionais, nesse sentido, a escola pode ser um espaço de sensibilização para a utilização destes, como forma de conservação dos recursos vegetais" (ALMEIDA, 2018, p. 53).

\section{Considerações finais}

Os povos indígenas possuem uma gama de saberes e, ao contrário do que muitos acreditam, existe entre eles um processo educacional diferenciado, no qual os conhecimentos são transmitidos através da oralidade, observação e prática. Entre esses saberes estão o conhecimento etnobotânico ou a relação entre homens e plantas. Por terem tradicionalmente uma relação de interdependência com a natureza, esses conhecimentos foram sendo acumulados ao longo do tempo.

Não diferente dos povos indígenas em geral, o povo Paiter Suruí, foco do estudo, possui uma íntima ligação com a natureza, principalmente com as plantas, delas vinham os alimentos, a madeira e a palha para a construção de moradias e canoas, os cocos e as sementes para fabricação de artesanato, da taquara sai o arco e flecha. Há também as plantas utilizadas para fins medicinais, como citadas no decorrer do texto, que eram de grande importância para a saúde da comunidade.

É notório que após o contato com os povos não indígenas, muitos desses conhecimentos vêm se perdendo e caindo em desuso, e infelizmente o ambiente escolar tem contribuído para isso ao longo do tempo, não valorizando o etnoconhecimento. No entanto, tem emergido um movimento em prol de uma educação indígena que respeite e valorize esses conhecimentos, dialogando entre os conhecimentos tradicionais e científicos e que ambos sejam complementos e não oposição.

\section{Referências}

ALBUQUERQUE, U. P. Introdução à Etnobotânica. 2. ed. Rio de Janeiro: Interciência, 2005.

\section{ALMEIDA SILVA, A. Territorialidades, identidades e marcadores territoriais Kawahib da Terra Indígena Uru-Eu-Wau-Wau em Rondônia. Jundiaí: Paco Editorial, 2015.}

ALMEIDA, E. R. Educação, Etnobotânica e plantas medicinais: um estudo de caso no curso técnico em agroecologia (Instituto Federal de Educação, Ciência e Tecnologia, Campus Cacoal, Rondônia, Brasil). 2018. 152 f. Tese (Doutorado) - Programa de Pós-Graduação em Educação em Ciências e Matemática, Universidade Federal de Mato Grosso, Cuiabá, 2018.

ALMEIDA, M. Z. Plantas medicinais. 3. ed. EDUFBA: Salvador, 2011.

BAVARESCO, A. et al. Pamine: o renascer da floresta. Brasília: Supernova Design, 2011. 
BRASIL. Resolução CNE/CEB N ${ }^{\circ}$ 5, de 22 de junho de 2012. Diário Oficial da União, Brasília, DF, 25 jun. 2012, Seção 1, p. 7.

CARDOZO, I. B. (Org.). Paiterey Garah: terra indígena Sete de Setembro. Porto Velho: Kanindé, 2011.

CARVAlho, A. C. B. et al. Aspectos da legislação no controle dos medicamentos fitoterápicos. Amazonas. FUCAPI. Revista T\&C Amazônia, ano v, n.11, p. 26-32, Manaus. 2007.

COIMBRA JR, C. E. A. Estudos de ecologia humana entre os Suruí do Parque Indígena Aripuanã, Rondônia: Plantas de importância econômica. Boletim do Museu Paraense Emilio Goeldi, Antropologia, v. 2, n. 1, p. 37-55, 1985.

DIAS, C. S.; SURUÍ, N. D. Educação escolar indígena: um novo modelo de educação para o povo Paiter Suruí. In: JESUS, S. N. et al (Orgs.). Povos e comunidades tradicionais: perspectivas além da epistemologia. Curitiba: CRV, 2017. p. 47-56.

DIAS, C. S. et al. Práticas tradicionais na gestação e no parto das mulheres Paiter Suruí. In: JESUS, S. N. et al (Orgs.). Povos e comunidades tradicionais: os sujeitos e seus deslocamentos. Curitiba: CRV, 2019. p. 37-47.

FARNSWORTH, N. R. Screening plants for new medicines. In: WILSON, E. O. (Ed.). Biodiversity. Washington, DC: National Academic, 1988.

FREIRE, P. Pedagogia da tolerância. São Paulo: UNESP, 2004.

HUBERT, R. História da pedagogia. São Paulo: Companhia Editora Nacional, 1976.

KFFURI, C. W. Etnobotânica de plantas medicinais no município de Senador Firmino (Minas Gerais). 2008. 88 f. Dissertação (Mestrado) - Programa de Pós-Graduação em Fitotecnia, Universidade Federal de Viçosa, Viçosa, 2008.

KOVALSKI, M. L.; OBARA, A. T. O estudo da etnobotânica das plantas medicinais na escola. Ciência \& Educação, Bauru, v. 19, n. 4, p. 911-927, 2013.

LINDENMAIER, D. S.; PUTZKE, J. Estudo etnobotânico em três comunidades Mbya/Guarani na região central do Rio Grande do Sul, Brasil. Revista Caderno de Pesquisa, Série Biologia, v. 23, n. 3, p. 6-18, 2011.

LUCIANO, G. S. O índio brasileiro: o que você precisa saber sobre os povos indígenas no Brasil de hoje. Brasília: MEC/SECAD; Rio de Janeiro: LACED/Museu Nacional, 2006.

MARTINS, A. G. et al. Levantamento etnobotânico de plantas medicinais, alimentares e tóxicas da Ilha do Combu, Município de Belém, Estado do Pará, Brasil. Revista Brasileira de Farmacognosia, v. 86, n. 1, p. 21-30, 2005. 
METAREILÁ. Oficina de identificação das plantas medicinais é realizado com os Paiter Suruí. Cacoal, 29 nov. 2018. Disponível em: <https://www.paiter.org/oficina-de-identificacaodas-plantas-medicinais-e-realizado-com-os-paiter-surui/>. Acesso em: 09 out. 2020.

METAREILÁ. Plano de ação participativo para o desenvolvimento de uma economia racional e de manejo sustentável dos recursos naturais da Terra Indígena Sete de Setembro. Pesquisas, consolidação e análise de dados culturais e demográficos, redação geral e organização dos textos: Maria do Carmo Barcellos. Terra Indígena Sete de setembro, Cacoal, fevereiro de 2010.

MINDLIN, B. Nós Paiter: os Suruí de Rondônia. Petrópolis: Editora Vozes, 1985.

PAPPIANI, A.; LACERDA, I. (Orgs.). Histórias do começo e do fim do mundo: o contato do povo Paiter Suruí. São Paulo: Okore, 2016.

PRODANOV, C. C; FREITAS, E. C. Metodologia do trabalho científico: métodos e técnicas da pesquisa e do trabalho acadêmico. 2. ed. Novo Hamburgo: FEEVALE, 2013.

RODRIGUES, V. E. G.; CARVALHO, D. A. Levantamento etnobotânico de plantas medicinais do domínio cerrado na região do Alto Rio Grande - Minas Gerais. Ciência Agrotécnica, v. 25, n. 1, p. 102-123, jan./fev., 2001.

SANTOS, A. M. S.; LIMA, M. E. M. Medicina tradicional e ocidental no Alto Rio Negro. O papel dos rezadores em São Gabriel da Cachoeira (AM). In: BUCHILLET, D. (Org.). Medicinas Tradicionais e Medicina Ocidental na Amazônia. Belém: MPEG/CNPq/SCT/PR/CEJUP/UEP, 1991. p. 229-240.

SANTOS, M. G. et al. Conhecimento e uso da medicina alternativa entre alunos e professores do primeiro grau. Revista Saúde Pública, v. 29, n. 3, p. 221-227, 1995.

SCANDIUZZI, P. P. Educação indígena x educação escolar indígena: uma relação etnocida em uma pesquisa etnomatemática. São Paulo: Editora: UNESP, 2009.

SILVA, V. A.; ALBUQUERQUE, U. P. Técnicas para análise de dados etnobotânicos. In: ALBUQUERQUE, U. P.; LUCENA, R. F. P. Métodos e técnicas na pesquisa etnobotânica. Recife: NUPEEA, 2004. p. 63-88.

SIQUEIRA, A. B. Etnobiologia como Metodologia no Ensino de Ciências. Anais do IV Simpósio sobre Formação de Professores/SIMFOP. Universidade do Sul de Santa Catarina, maio, 2012.

SIQUEIRA, A. B.; PEREIRA, S. M. Abordagem etnobotânica no ensino de Biologia. Revista Eletrônica do Mestrado em Educação Ambiental, v. 31, n.2, p. 247-260, jul./dez. 2014.

SURUÍ, A. Plantas medicinais do povo Paiter Suruí: Sabedoria tradicional na aldeia Gabgir. 2015. 29 f. Trabalho de conclusão de curso (Graduação) - Licenciatura em educação básica Intercultural, Universidade Federal de Rondônia, Ji-Paraná, 2015.

SURUÍ, C. Reflorestamento da Terra Indígena Sete de Setembro: uma mudança da percepção e conduta do povo Paiter Suruí? 2013. 63 f. Dissertação (Mestrado) - Centro de Desenvolvimento Sustentável, Universidade de Brasília, Brasília, 2013. 
SURUÍ, P. Tradicionais Plantas Medicinais Do Povo Paiter Suruí, Cacoal - Rondônia. 2017. 46 f. Trabalho de conclusão de curso (Graduação) - Bacharel em Enfermagem, Instituição de Ensino Superior de Cacoal - FANORTE, Cacoal, 2017.

TRIVIÑOS, A. N. S. Introdução à pesquisa em ciências sociais: a pesquisa qualitativa em educação. São Paulo: Atlas, 1987.

VIU, A. F. M. et al. Etnobotânica: uma questão de gênero? Revista Brasileira de Agroecologia, v.5, n.1, p. 138-147, 2010.

Recebido em agosto de 2020.

Aprovado em novembro de 2020. 